\title{
QUESTÕES SOCIOAMBIENTAIS E ENSINO DA QUÍMICA: PERSPECTIVAS E DEMANDAS NO CONTEXTO DO ENEQ 2010-2012
}

\author{
Luciano Gomes de Andrade ${ }^{1}$ \\ Jessica Karoline Costa Barros ${ }^{2}$ \\ Elizandra Rego Vasconcelos ${ }^{3}$
}

Resumo: A pesquisa investigou trabalhos submetidos no Encontro Nacional de Ensino de Química-ENEQ. O objetivo foi estudar temas socioambientais e identificar as principais linhas temáticas voltadas para o ambiente. Foram organizados e analisados os trabalhos apresentados nos anos de 2010 e 2012 que tiveram como foco a temática ambiental. Os resultados mostram as linhas temáticas encontradas: $46 \%$ de trabalhos sobre Química ambiental, 7\% Química verde e $46 \%$ CTSA. A grande maioria destes periódicos tratam esses temas socioambientais de forma contextualizada e interdisciplinar.

Palavras-chave: Ensino de Química; CTSA; Meio Ambiente.

\footnotetext{
1 Universidade Federal do Amazonas. E-mail: lucianogomesdeandrade@gmail.com

2 Universidade Federal do Amazonas. E-mail: jessicabarros09@gmail.com

3 Universidade Federal do Amazonas. E-mail: elizandravasconcelos@hotmail.com
} 


\section{Introdução}

No século $X X$ as mudanças ocorridas no plano socioeconômico e cultural, fundamentadas no processo de globalização da economia capitalista, vêm interferindo na dinâmica e na estrutura da sociedade, instituindo uma crise socioambiental. Nesse contexto, o conceito de desenvolvimento tem sido relacionado, quase que exclusivamente, ao crescimento econômico.

$\mathrm{Na}$ lógica do desenvolvimento como sinônimo de crescimento econômico os países pobres e em desenvolvimento têm aceitado penosas condições de destruição ambiental, ecológica, social, cultural e histórica para alcançar benefícios comerciais que aprisionam economias nacionais periféricas a um sistema global predatório e cruel (SEN, 2010).

Diante disso, a sustentabilidade do planeta tem sido pauta de discussões no mundo todo, em virtude da crise civilizatória que a humanidade experimenta atualmente, e que tem colocado dúvidas sobre o futuro da humanidade. Concomitante a isso, as relações entre Ciência, Tecnologia e Sociedade (CTS) têm sido alvo de muitas pesquisas no âmbito da educação em ciências. Em linhas gerais, a educação CTS pretende a construção de conhecimentos que estejam associados a pensamentos e atitudes que tenham por foco fundamental a compreensão das problemáticas geradas pela interação entre ciência e tecnologia no meio social (SILVEIRA; BAZZO, 2009).

Assim, compreende-se que um dos objetivos de um ensino CTS no processo de ensino e aprendizagem de ciências é a construção de pensamentos articulados que se materializem em condições de aprendizagem que tenham sentido e finalidade na vida cotidiana geral (VIEIRA; VIEIRA, 2005). Nesse sentido, a temática socioambiental atende ao imperativo de contribuirmos para uma educação alicerçada na cidadania consciente da atual situação de emergência planetária e, ao mesmo tempo, favorecer a adoção das necessárias medidas para conformação de um futuro previsível.

Nesse contexto, a Amazônia tem lugar de destaque por apresentar natureza única, multicultural, biológica e socialmente diversificada, além de se constituir cenário de conflitos socioambientais. São vários os projetos, as iniciativas, as instituições governamentais e não-governamentais que aqui se inserem sob a prerrogativa do desenvolvimento sustentável (RIBEIRO, 2006). Entretanto, segundo Becker (2009) e Gonçalves (2008), apesar dos esforços para garantir o desenvolvimento, a preservação, o uso racional de recursos e a sensibilização social, a Amazônia tem sido espoliada no seu patrimônio socioambiental.

Essa pesquisa investigou os trabalhos submetidos no Encontro Nacional de Ensino de Química (ENEQ) nos anos de 2010 e 2012, com o objetivo de estudar temas socioambientais, identificar as principais linhas temáticas no ensino de Química voltadas para o meio ambiente, verificar o número de publicações contendo os assuntos: biodiesel, biocombustíveis, chuva ácida, formação de professores, reciclagem. E relação CTSA com o ensino de 
química. Certamente, no sentido de contextualizar o conhecimento de química trabalhado na educação básica e superior.

\section{Relações CTSA e o ensino de química}

As primeiras relações entre Ciência e Tecnologia (C\&T), restringiam-se ao pensamento em que a combinação entre ambas só acrescentaria benefícios a sociedade. Essa convicção deve-se, por um lado, à compreensão da ciência como neutra e objetiva, ou seja, uma instituição autônoma, regida por si própria e sem qualquer relação com o meio social. E por outro, ao entendimento da tecnologia como sinônima de supremacia, desenvolvimento e dominação socioeconômica (SHOR, 2007).

Entretanto, as últimas décadas serviram para ratificar que a ciência "[...] longe de ser autônoma, estaria presa as suas estruturas sociais de determinação" (SHOR, 2007, p. 338). Por isso, a comunidade acadêmica tem entendido, nas últimas décadas, que o ensino de ciências precisa ser contextualizado socialmente. Deste modo, em meados de 1960, alguns desastres constituíram-se verdadeiros indícios para demonstrar que essa articulação não era tão confiável quanto se acreditava. Silveira e Bazzo (2009. p. 686) citam o seguinte:

O projeto Manhattan [projeto para o desenvolvimento da bomba atômica] e sua aplicação em Hiroshima, além de outros casos de desenvolvimentos tecnológicos vinculados à guerra e utilização militar, [...], representaram o primeiro ponto de inflexão da concepção otimista do caráter benfeitor da ciênciatecnologia, junto com as preocupações dos problemas ambientais.

Esses fatos, juntamente com a divulgação de vários casos de impactos ambientais relacionados ao desenvolvimento tecnológico, a revolução industrial e a publicação da obra A estrutura das Revoluções Científicas de Thomas Kuhn, em 1962, causou uma reviravolta nas discussões acadêmicas sobre C\&T. A partir de então, outros aspectos começaram a ser incluída nas discussões sobre as relações C\&T, agregando outros fatores ligados a realidade social envolvida.

Assim, formou-se no âmbito da educação científica uma iniciativa conhecida como movimento CTS que tem por objetivo fomentar "[...] a busca de participação, de democratização nas decisões em temas/problemas sociais que envolvam ciência-tecnologia [...]" (MUENCHEN; AULER, 2007. p.422). Nessa perspectiva, as discussões evoluíram, no campo educacional, no sentido de uma formação que vá além da "capacitação" profissional de professores e estudantes, mas abranja a dimensão ética e cidadã, e culmine na busca pela participação dos sujeitos. A contextualização social da ciência, 
nesse âmbito, constitui-se fator determinante para 0 alcance dos novos/renovados objetivos da educação científica.

De acordo com Cassiani e Linsingen (2009), as relações CTS envolvem o conhecimento científico de modo que este seja abordado segundo sua esfera política, econômica e socioambiental. Isso, com a finalidade de que o conhecimento seja discutido a partir de um contexto, e não isoladamente como se tornou comum na prática didática realizada por muitos professores, conforme o método tradicional de ensino. Sendo assim, o enfoque CTS, no ensino de ciências, também significa mudanças na maneira como professores e estudantes interagem com o conhecimento.

Educar, numa perspectiva CTS é, fundamentalmente, possibilitar uma formação para maior inserção social das pessoas no sentido de se tornarem aptas a participar dos processos de tomadas de decisões conscientes e negociadas em assuntos que envolvam ciência e tecnologia. Em outras palavras, é favorecer um ensino de/sobre ciência e tecnologia que vise à formação de indivíduos com a perspectiva de se tornarem cônscios de seus papéis como participantes ativos da transformação da sociedade em que vivem (CASSIANI; LINSINGEN, 2009, p.135)

Em verdade, essa preocupação em desenvolver nos sujeitos envolvidos uma faculdade da razão que os permita perceber seus próprios atos em relação ao conhecimento construído cientificamente e às consequências desses sobre o ambiente em que vivem, é o ponto em que se intersectam as noções de sustentabilidade e as orientações CTS.

Silveira e Bazzo (2009) destacam que o ensino de uma ciência descontextualizada socialmente, contribuiu (e ainda contribui) para a continuidade de uma concepção ingênua sobre a ciência, descrita, essencialmente, como uma "[...] concepção essencialista e triunfalista, na qual se presume que mais ciência produz mais tecnologia que gera mais riqueza e, consequentemente, mais bem-estar social' (Silveira; Bazzo, 2009. p. 685). Entretanto, este raciocínio já foi superado teoricamente tanto no âmbito da própria educação científica quanto pelas teorias econômicas nos moldes do desenvolvimento sustentável (SACHS, 2008).

Para Shor (2007), a crença cega nos benefícios que a ciência e a tecnologia poderiam acrescentar a sociedade está relacionada à "força" presente nas explicações científicas que acabam influenciando fortemente as relações sociais. Nessa lógica, as explicações científicas fundamentaram o desenvolvimento tecnológico. E esse, por sua vez, tornou-se a principal base do desenvolvimento econômico mundial. Podemos citar que são vários os "[...] desastres vinculados ao desenvolvimento científico-tecnológico: vazamentos de resíduos poluentes, acidentes nucleares em reatores civis e de transportes militares, envenenamentos por produtos farmacêuticos, derramamentos de petróleo etc., que serviram para confirmar a necessidade de se revisar a política científico-tecnológica" (SILVEIRA; BAZZO, 2009. p.685). 
As adversidades socioambientais geradas por uma visão de ciência ingênua e reducionista têm levado a humanidade a produzir tecnologias que nem sempre visam à qualidade de vida. $E$, opostamente, e muitas vezes, pretende tão somente o progresso tecnológico a serviço do mercado econômico que gera, nesta condição, exclusão, miséria, entre outros resultados. Assim, se o desenvolvimento tem por sustentáculo a tecnologia, que não existe e nem evoluí sem o conhecimento científico, é impossível pensar qualquer transformação socioambiental separando estas três esferas.

Portanto, ciência e tecnologia precisam ser estudadas a partir da reflexão sobre os vários problemas que podem ocasionar no contexto socioambiental geral (PINHEIRO; SILVEIRA; BAZZO, 2007). Diante desse cenário, Vieira e Vieira (2005) defendem que a perspectiva CTS torna-se eminente no âmbito do ensino de ciências, por dois motivos: (1) a velocidade com que se produzem revoluções científicas e (2) a capacidade com que a ciência e a tecnologia têm incidido sobre uma atitude cidadã responsável. Nesse sentido, ensinar uma ciência de verdades absolutas torna-se inviável e cada vez mais difícil. E o mesmo acontece com as tentativas de obscurecer as relações cada vez mais evidentes entre ciência, tecnologia, sociedade e sustentabilidade - da vida e do planeta.

Entendemos que a abordagem de conhecimentos científicos dentro de um contexto bem esclarecido e com uma finalidade social colabora para que 0 ensino e a aprendizagem em ciências, construída nas escolas, não sejam inertes. E nesse pensar, a formação científica realizada em nosso tempo de vida viabiliza algumas condições para que as gerações futuras tenham a chance de conhecer, compreender e interagir com um mundo semelhante ao que nós habitamos nos dias atuais. $E$ isso se coaduna com noção de sustentabilidade.

Além do mais, para que o desenvolvimento científico e tecnológico seja menos excludente, é necessário que se levem em conta os reais problemas da população, os riscos técnico-produtivos e a mudança social. Por isso, faz-se necessário ter uma visão interativa e contextualizada das relações entre ciência, tecnologia, inovação e sociedade e, muito especialmente, das políticas públicas mais adequadas para se gestionarem as oportunidades e perigos que envolvem uma mudança técnica. Ou seja, a questão não é tanto se a ciência é boa ou não, mas sim se pode melhorar e como (SILVEIRA; BAZZO,2007. p. 686).

Segundo a pesquisa de Silveira e Bazzo (2009, p. 681), sobre as concepções "que as pessoas envolvidas [...] com o processo de desenvolvimento de inovações tecnológicas dentro de IEBTs (Incubadoras de Empresas de Base Tecnológica) do Paraná possuem sobre ciência, tecnologia, inovação e suas relações com o contexto social", a maioria dos sujeitos investigados ainda acredita que o progresso científico e tecnológico funciona como uma alavanca para o desenvolvimento econômico. Esse resultado pode estar associado ao rigor e a autoridade outorgada à ciência e à tecnologia como geradoras de maior qualidade de vida social, mediada pelo

revista brasileira educação ambiental 
desenvolvimento técnico/industrial, de mercado e econômico. Essa construção de que o aumento da renda é o fator mais importante para o equilíbrio socioambiental, certamente, está ainda relacionado ao mote, tão propalado durante a revolução industrial, ou seja, é preciso fazer crescer o bolo para depois distribuí-lo (VEIGA, 2008). Os processos e problemas desencadeados por meio desse pensar já demonstraram a impertinência do mesmo.

Afinal, é indiscutível que a inovação tecnológica é necessária, seja do ponto de vista da sociedade como um todo, que precisa dela para melhorar a sua qualidade de vida e do meio ambiente, ou do ponto de vista das empresas/indústrias, que precisam sobreviver no mercado, tendo também lucro. A questão é: será que a inovação tecnológica precisa ser um mal, para ser lucrativa? Será que uma formação diferenciada dos geradores de tecnologia (engenheiros, tecnólogos), que promova uma mudança de visão desses profissionais, não seria o caminho para abrandar esse mal? (SILVEIRA; BAZZO, 2007. p.688).

Em verdade, quando se levanta a questão sobre uma formação diferenciada e direcionada para a construção de um novo olhar sobre a tecnologia, a qualidade de vida e o meio ambiente, já há indicativos da necessidade de discutir os três pilares da sustentabilidade, de um modo geral, quais sejam: justiça social, eficiência econômica e equilíbrio ambiental, nos termos de Sachs (2008) e Veiga (2005). Portanto, compreendemos que o estudo realizado por Silveira e Bazzo (2007) já enseja algumas articulações entre CTS, ensino de ciências e sustentabilidade.

Diante disso, é evidente a necessidade de um processo de alfabetização sociocientífica sobre os temas que se inserem nas relações entre ciência, tecnologia, sociedade (CTS) e sustentabilidade. Esse processo diz respeito à interlocução e à compreensão de informações e conhecimentos que envolvam temáticas das áreas de ciências e de tecnologia, com enfoque a suas interações, as quais nos auxiliem a compreender e a interpretar a realidade em que vivemos.

O ensino de química com ênfase em ambiente pode ser considerado um instrumento didático que facilita a compreensão do conhecimento de química na sociedade geral. A escola é um espaço adequado para contextualizar esse conhecimento com estudantes da educação básica, pois nesse momento é possível discutir a importância de alguns conceitos no dia a dia, mantendo uma conexão da disciplina com a realidade.

A temática socioambiental é de suma importância e relevância em toda e qualquer área, principalmente aquelas vinculadas à educação. Deste modo, tem se buscado contextualizar o ensino de Química com os temas socioambientais. De acordo com os PCNS os conceitos químicos não devem ser ensinados de modo isolado e sim fazer uma relação entre o conhecimento científico e o mundo real. Portanto, evidencia-se a relevância da inserção de questões atuais, como as questões socioambientais, no ensino da Química, 
pois auxilia a desenvolver uma consciência ambiental, sendo assim, interligando ambas.

Não são poucos os trabalhos do ENEQ que mencionam os conhecimentos químicos com problemas socioambientais. Lima (2012) ao investigar a importância da Educação Ambiental - EA no ensino da Química, com o objetivo de contribuir para a mudança comportamental do aluno referente ao meio ambiente, chegou à conclusão que os temas socioambientais são uma maneira encontrada de complementar a teoria para melhor assimilação e despertar o interesse dos alunos a desenvolver um senso crítico e investigativo.

Medeiros (2010), ao explorar a produção do lixo com o objetivo de formar alunos mais conscientes para lidar com as questões ambientais, chegou à conclusão que a abordagem desse tema facilitou a compreensão dos alunos, da problemática dos resíduos sólidos e sua contextualização com a química. Ou seja, temas socioambientais associados a conceitos de química podem tornar os assuntos mais próximos da realidade e favorecer a aprendizagem.

Campos (2010), ao investigar a formação de professores de Química, com o objetivo de saber se as concepções de meio ambiente e educação ambiental influenciavam a forma como os professores propõem o ensino voltado às questões ambientais, chegou à conclusão que os professores veem a Química como um 'instrumento' para práticas educativas que visam promover atitudes ambientalmente corretas com uma visão de meio ambiente como pano de fundo para a vida humana. Isso privilegia uma leitura reducionista da temática ambiental. Percebe-se, que as questões socioambientais são possibilidades de reflexões didáticas para a contextualização da linguagem da Química para o cotidiano do aluno.

Nesse contexto, os Parâmetros Curriculares Nacionais - PCNs (ensino médio) ao discutirem o ensino de Química salientam que este não pode ficar apenas centrado em conceitos ou memorizações, mas precisa buscar uma compreensão fundamental que possibilite atribuir sentidos ao conhecimento científico em sala de aula. Os ensinos por meio de temas que são relevantes para a sociedade, tornam-se uma alternativa para relacionar a dimensão social com a própria ciência Química, conforme:

[...] é preciso objetivar um ensino de química que possa contribuir para uma visão mais ampla do conhecimento, que possibilita melhor compreensão do mundo físico e construção da cidadania, colocando em pauta, na sala de aula, conhecimentos socialmente relevantes, que façam sentido e possam se integrar à vida do aluno (BRASIL, 2000, p. 32).

Os PCNEM têm reorientado os objetivos do ensino de química, especialmente, a maneira de associa-locom temas socioambientais, como: bicombustível, biodiesel, reciclagem de plásticos, reutilização de óleos de comestíveis, etc. Certamente, isto se relaciona com as demandas 
socioambientais que exigem do ensino de Química maiores relações com a vida em sociedade.

Nesse sentido, é interessante que o ensino de Química também tenha como objetivo problematizar questões socioambientais. $E$ que esta pretenda uma transformação de atitudes em relação ao ambiente. Isto, certamente, perpassa pelo reconhecimento de valores éticos e esclarecimentos de conceituais para uma ação educativa, direcionada para o bem-estar social global.

Atualmente fala-se constantemente em questões ambientais. Dentre as principais temáticas estão as seguintes: emissão de gases poluentes para atmosfera, contaminação das águas e efluentes, mudanças climáticas, chuva ácida. Nesse sentido, a relação do ambiente com a Química tem sido destacada no âmbito acadêmico-científico. Isso tem resultado no surgimento de áreas ou linhas de pesquisa como: Química Ambiental (QA) e Química Verde (QV) resultam numa discussão entre relações cientificas sociais e econômicas.

Segundo Hill et al. (2013, pp.24-25) a QA trata dos processos ambientais que possibilita uma maior margem de lucro para as industriais. A QV é uma área nova que surgiu há pouco tempo [...] "para aprimoramento de processos com objetivos de redução na geração de resíduos e efluentes tóxicos, bem como a menor produção de gases indesejáveis ao meio ambiente". A QV se interessa primordialmente por processos ambientalmente responsáveis, sem ser inerentemente de interesse ambiental.

\section{Desenho metodológico}

Trata-se de uma pesquisa bibliográfica que buscou quantificar e analisar artigos que tratassem do ensino de Química relacionando- o a temas socioambientais. Foram escolhidos os trabalhos submetidos ao ENEQ em suas duas últimas edições (2010 e 2012), por ser um evento tradicional e importante para as pesquisas na aérea de ensino da Química.

A pesquisa foi desenvolvida em duas etapas: na primeira foi realizada a seleção dos artigos por meio do seguinte critério: estar relacionado a Educação Ambiental. Nas publicações selecionadas constavam propostas metodológicas para formações de professores, aplicações de experimentos, análises de livro didático, trabalhos com resultados originais e trabalhos de revisão.

A segunda etapa constituiu-se na classificação/categorização desses artigos em três linhas temáticas, quais sejam: QA, QV e CTSA. Nesse processo foi utilizado o software Excel para organização, contagem dos artigos encontrados e gerar os gráficos na forma de colunas. 


\section{Resultados e discussão}

Foram analisados 87 artigos publicados nos ENEQs sendo: 55 resumos e 32 trabalhos completos, nos anos de 2010 e 2012, na área de EA. Nota-se a superioridade de resumos em relação a artigos completos (Figura 1). Isto pode evidenciar que grande parte das pesquisas apresentadas no evento ainda são inicial ou estão em andamento o que pode estar ligado a novidade das áreas ou associações que os professores têm realizado entre a Química e as questões socioambientais no âmbito do ensino.

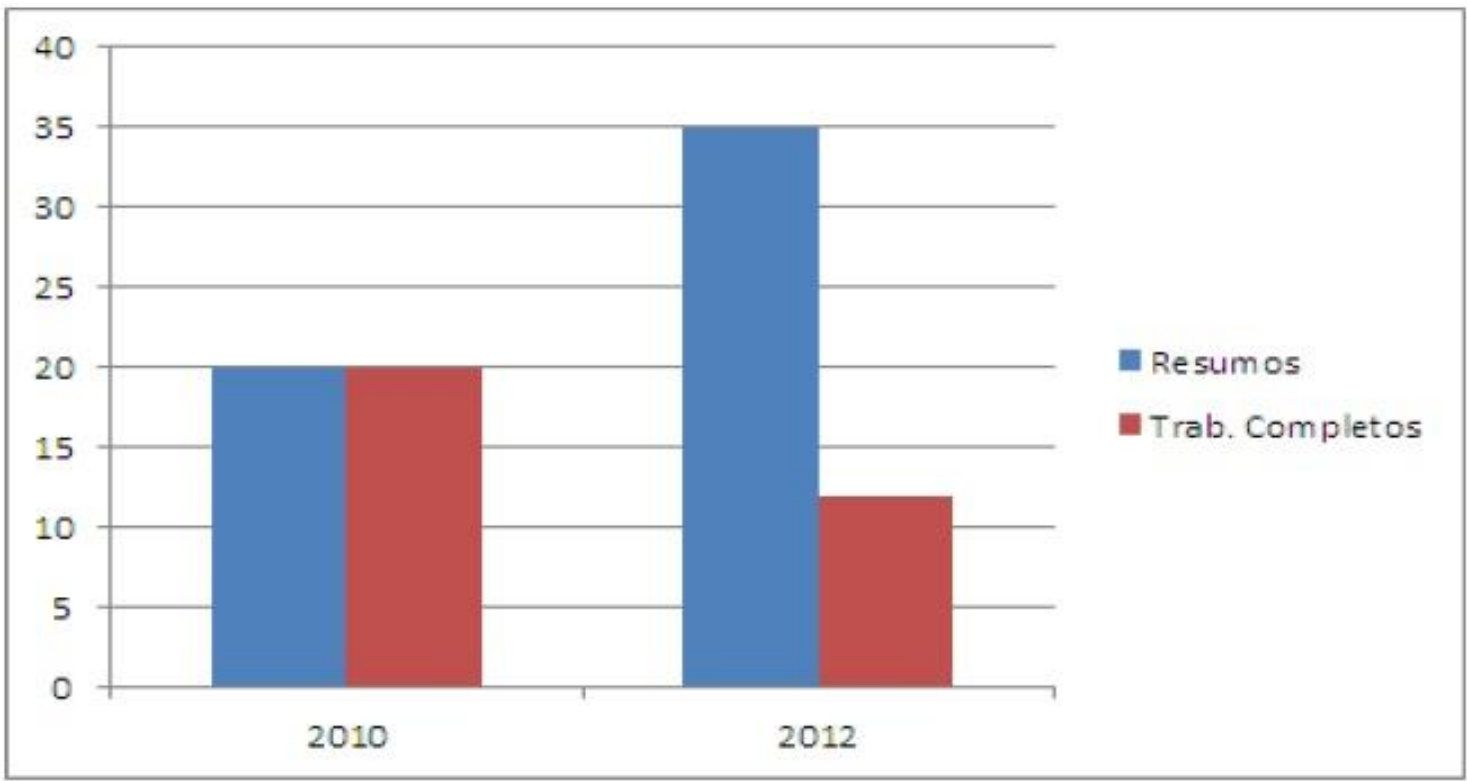

Figura 1: ENEQ - 2010 e 2012 - Análises de Trabalhos.

Os temas socioambientais mais identificados foram os seguintes: desperdício e análise de água; aquecimento global; reciclagem de garrafas PET; resíduos sólidos e chuva ácida. Em relação às principais linhas temáticas encontrou-se: $46 \%$ de trabalhos ligados a Química ambiental, 7\% Química verde e $46 \%$ CTSA. A grande maioria destes periódicos tratam esses temas socioambientais de forma contextualizada e interdisciplinar para uma melhor compreensão dos termos químicos. 


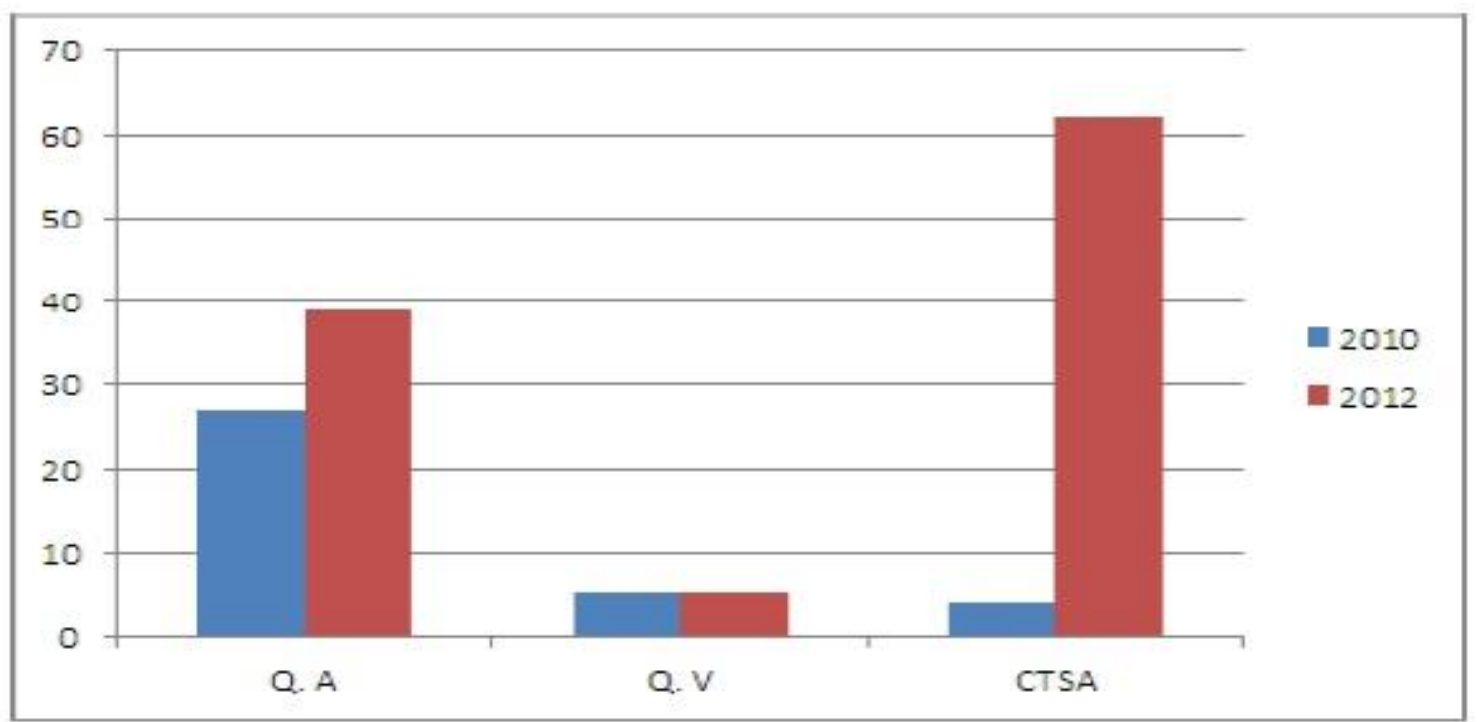

Figura 2: ENEQ - 2010 e 2012 - linhas temáticas - Química ambiental (Q.A), Química Verde (Q.V) e Ciência,Tecnologia ,Sociedade e Ambiente(CTSA)

Isto, certamente está de acordo com as demandas encontradas no PCNEM (2012) os quais indicam como caminhos para contextualização do ensino de Química a transversalidade, interdisciplinaridade e a ênfase na relação dos assuntos inerentes a disciplina com os acontecimentos do dia a dia das pessoas. Nesse sentido, os temas socioambientais tornam-se meios pelos quais a Química pode ser percebida pelos sujeitos a partir de interesses coletivos.

Por outro lado, é possível perceber o crescimento de pesquisas em torno da QA e do CTSA envolvendo a disciplina Química. Certamente, isto tem a ver com a 'tradição' da EA que pode estar influenciando o ensino e aprendizagem de Química nas escolas. Ademais, o CTSA também se configura em uma tendência no ensino e aprendizagem de ciências que já compõe o currículo de diversos cursos de Licenciatura e programas de pós-Graduação no cenário brasileiro. Hill et al. (2013) concluem que a QA está ligada ao interesse econômico, por isso, o interesse em desenvolver trabalhos ligados a essa aérea são maiores.

A partir dos dados pode-se constatar que a QV ainda é discutida em menor número de trabalhos no evento. Em países em desenvolvimento, como o Brasil ainda é uma aérea emergente, derivada da QA, sendo mais discutida em países com a renda per capita maior, como os EUA, o país de origem da QV. Segundo Rocha (2009), são países onde há uma maior produção de resíduos sólidos e semissólidos de origem industrial, decorrente ao número elevado de consumismo e ao poder monetário, devido a isso houve alta expansão de trabalhos vinculados a QV. 
Dado que a Química Verde visa o desenvolvimento de tecnologias e materiais incapazes de causar poluição, idealmente, a sua aplicação pode promover a passagem da abordagem tradicional de 'comando e controle' à desejável 'prevenção' de poluição, tornando desnecessárias as remediações dos impactos ambientais frequentemente observados (CORREA, 2009, p.9-22).

Nesse contexto, verificamos na QV difere da QA por tratar de processos não comportamentalista, mas sim de conscientização para prevenção do aumento da produção de resíduos. Segundo Collins (1995) a QV começou a ser pesquisa a cerca de 10 anos nos EUA, local onde esta tem sido mais estudada e recentemente o Brasil tem se interessado por essa área. Acreditase que isso pode significar a preocupação em âmbito nacional tanto com a geração de resíduos quanto o tratamento a eles dispensado pelo governo, haja vista que o Brasil tem crescido em tecnologias de mercado e tecnologias alternativas de 'controle' ambiental.

\section{Considerações finais}

Finalmente, as análises realizadas demonstram que apesar de crescentes, ainda são pouco discutidos no Brasil, notadamente no ENEQ nos anos de 2010 e 2012 as linhas temáticas que relacionam o ensino de Química a dimensão ambiental. Destaca-se a importância dessa pesquisa para a sociedade geral, pois é necessário que os estudantes de Química sejam capazes de lidar com problemas relacionados à vida real, fazer críticas e tomar decisões pertinente ao cotidiano e sair do chamado analfabetismo científico. Notadamente, no âmbito das questões socioambientais, tão propaladas atualmente.

A grande maioria das pesquisas apresentadas no ENEQ tratam esses temas socioambientais com a importância devida, de forma contextualizada para uma melhor compreensão dos termos químicos. Por outro lado, a QV ainda pouco discutida tem conectado o ensino de química ligado a temática ambiental a diferentes áreas do conhecimento caracterizando o processo educativo como interdisciplinar.

Diante disso, percebe-se que é relevante a associação do ensino com temas ambientais nas escolas e na formação de professores de Química para que as pessoas possam compreender a realidade das problemáticas ambientais com a profundidade que poderá fomentar possíveis soluções globais.

\section{Referências}

BRASIL. Ministério da Educação. Secretaria de Educação Média e Tecnológica. Parâmetros curriculares nacionais: ensino médio. Brasília: Ministério da Educação e Cultura/Secretaria de Educação Média e Tecnológica, 2000. 
CASSIANI, S.; LINSINGEN, I, V. Formação inicial de professores de ciências: perspectiva discursiva na educação CTS. Educar, Curitiba, n. 34, p. 127-147, 2009.

CAMPOS et al .Concepções de professores sobre meio ambiente e educação ambiental e suas influencias no ensino de química. Anais do XV Encontro Nacional de Ensino de Química (XV ENEQ), Brasília, DF,21 a 24 de julho de 2010.

HILL, J.; KUMAR, D.D.; VERMA, R.K. Challenges for Chemical Education: Engaging with Green Chemistry and Environmental Sustainability. The Chemist. v.86, p.24-31, 2013.

LIMA, M.C.M.; OLIVEIRA, G.L.; RIBEIRO, S.N. A implantação de uma Horta orgânica: Uma alternativa para a educacao ambiental no ensino de química. Anais do XV Encontro Nacional de Ensino de Química (XV ENEQ) e X Encontro de educação química da Bahia ( X EDUQUI), 2012, Salvador , Bahia, 2012 .p. 1.

MEDEIROS et al. Lixo um problema a ser resolvido por todos Anais do XV Encontro Nacional de Ensino de Química (XV ENEQ), Brasília, DF,21 a 24 de julho de 2010.

MUENCHEN, C; AULER, A. Configurações curriculares mediante o enfoque CTS: desafios a serem enfrentados na educação de jovens e adultos. Ciência \& Educação, Bauru, v. 13, n. 3, p. 421-434, 2007.

SACHS, I. Desenvolvimento: includente, sustentável, sustentado. Rio de Janeiro: Garamond, 2008. 151 p.

SEN, A. Desenvolvimento como liberdade. São Paulo: Companhia das letras, 2010. 461p.

SHOR, T. Reflexões sobre a imbricação entre ciência, tecnologia e sociedade. ScientiaeStudia, São Paulo, v. 5, n. 3, p. 337-67, 2007.

SILVEIRA, R. M. C. F. BAZZO, W. Ciência, tecnologia e suas relações sociais: a percepção de geradores de tecnologia e suas implicações na educação tecnológica. Ciência \& Educação, Bauru, v. 15, n. 3, p. 681-694, 2009.

MUENCHEN, C; AULER, A. Configurações curriculares mediante o enfoque CTS: desafios a serem enfrentados na educação de jovens e adultos. Ciência \& Educação, Bauru, v. 13, n. 3, p. 421-434, 2007.

VIEIRA, C.T.; VIEIRA, R.M. Construção de práticas didático-pedagógicas com orientação CTS: impacto de um programa de informação continuada de professores de ciências do ensino básico. Ciência \& Educação, Bauru, v. 11, n. 2, p. 191-211, 2005.

VEIGA, J. E. Desenvolvimento sustentável: o desafio do século XXI. Rio de Janeiro: Garamond, 2005

ROCHA, J.C.; ROSA. A.H.; CARDOSO, A.A. Introdução à química ambiental. 2.ed.- Porto alegre: Bookman, 2009, 224 p.

Revbea, São Paulo, V. 11, № 1: 85-96, 2016. 